\title{
The Evaluation of Possibilities to Assess a Few Years After the Fire Forest Burnt Severity Using Multi-Spectral Satellite Data
}

\author{
Fedor V. Stytsenko ${ }^{\text {, Ilya A. Saigin }}{ }^{1,2}$, Sergey A. Bartalev ${ }^{1}$ \\ ${ }^{1}$ Space Research Institute, Russian Academy of Sciences, Moscow, Russia \\ fedor@d902.iki.rssi.ru \\ ${ }^{2}$ Lomonosov Moscow State University, Moscow, Russia \\ saiginilya95@mail.ru
}

\begin{abstract}
The results of experimental studies presented in this paper characterize the possibility of damaged forests quantitative state assessment in a few years after the fire according to multispectral satellite measurements. The necessary reference data on forest damage were collected during the ground surveys of test fire sites in the Republic of Komi and the Krasnoyarsk territory. The study showed that understory represented by grass and shrub vegetation has a significant impact on the values of vegetative indices during the active vegetation phase, and there is a need for local accounting of this factor.
\end{abstract}

Keywords: remote sensing, multi-spectral satellite images, spectral vegetation index, forest fire, burn severity, forest status

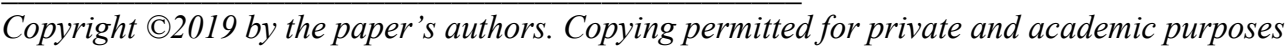




\title{
ИССЛЕДОВАНИЕ ВОЗМОЖНОСТЕЙ МНОГОЛЕТНЕГО МОНИТОРИНГА СОСТОЯНИЯ ПОВРЕЖДЕННЫХ ПОЖАРАМИ ЛЕСОВ НА ОСНОВЕ СПУТНИКОВЫХ ДАННЫХ
}

\author{
Ф.В. Стыценко ${ }^{\text {I, И.А. Сайгин }}{ }^{1,2}$ С.А. Барталев ${ }^{1}$ \\ ${ }^{1}$ Институт космических исследований РАН, Москва, Россия \\ fedor@d902.iki.rssi.ru \\ ${ }^{2}$ Московский государственный университет имени М.В. Ломоносова, Москва, Россия \\ saiginilya95@mail.ru
}

\begin{abstract}
Представленные в работе результаты экспериментальных исследований характеризуют возможности количественной оценки состояния поврежденных лесов через несколько лет после воздействия пожара по данным многоспектральных спутниковых измерений. Необходимые для исследований независимые опорные данные о повреждениях лесов огнем были собраны в ходе наземных обследований тестовых участков в республике Коми и Красноярском крае. На обоих тестовых участках была выявлена линейная взаимосвязь количественных показателей состояния лесов и вегетационных индексов. Выполненный анализ позволил сделать вывод о значительном влиянии послепожарного восстановления напочвенного растительного покрова на значения спектральных вегетационных индексов, полученных в активный период вегетации, и необходимости локального учета данного фактора.
\end{abstract}

Ключевые слова: дистанционное зондирование, многоспектральные спутниковые изображения, спектральные вегетационные индексы, лесные пожары, повреждения лесов, состояние насаждений

\section{Введение}

Пожары являются одним из наиболее мощных факторов воздействия на леса. Вызываемые пожарами последствия для древостоев могут варьировать от незначительных краткосрочных повреждений до полной их гибели, в зависимости от вида, интенсивности и продолжительности воздействия огня, а также породного состава, возрастной структуры и других характеристик древостоев. Оценка экономических и экологических последствий лесных пожаров требует своевременного получения объективных данных о состоянии поврежденных насаждений, в том числе, о наличии в их составе усыхающих и усохших деревьев. Поскольку масштабы ежегодного воздействия пожаров на леса России измеряются миллионами гектаров [1], данные дистанционного зондирования со спутников являются незаменимым инструментом для получения оценок такого рода на больших территориях.

Выполненные ранее исследования показали возможность использования спутниковых данных для оценки последствий пожаров [2-8]. Разработан и находит широкое применение метод дистанционной оценки пирогенных повреждений лесов [9], основанный на использовании уравнения связи вегетационного индекса RdSWVI с степенью дефолиации и дехромации лесов, и спутниковых данных, полученных непосредственно в год пожара. Применение данного метода позволило впервые получить оценки погибших в результате воздействия пожаров лесов на всей территории России [3]. Вместе с тем, полученные результаты не учитывают многолетний 
постпожарный отпад в лесах, а также ограничены в оценке состояния лесов, поврежденных осенними пожарами в поздней фазе вегетации. Вопрос использования спутниковых данных для оценки состояния лесов и её динамики в последующие за пожаром годы исследован в меньшей степени. Очевидно, что отражательные свойства поврежденных лесов могут меняться с течением времени, в частности, за счет развития травянистого и кустарникового напочвенного покрова, который может вносить различный вклад в регистрируемый спутниковым сенсором сигнал в зависимости от территории и условий произрастания деревьев. Как следствие, влияние этого фактора способно затруднять получение корректных и сопоставимых многолетних оценок степени повреждения лесов.

Настоящее исследование направлено на изучение зависимостей между отражательными характеристиками лесов, измеренными спутниковыми приборами через несколько лет после воздействия огня, и количественными индикаторами их состояния, полученными по результатам детальных наземных обследований насаждений.

\section{Получение опорных наземных данных}

В ходе исследования был проведен сбор наземных данных о поврежденных пожарами лесах в Республике Коми и Красноярском крае. Лесопатологические обследования проводились в июле и сентябре 2015 года и охватывали насаждения, поврежденные пожарами 2010-2013 годов. В ходе подготовки обследований были созданы предварительные карты стратификации гарей на основе индекса RdSWVI, что позволило исследовать участки, поврежденные пожарами в разной степени, от слабых повреждений древостоев до их полной гибели. Более подробная информация о тестовых участках и полученных данных представлена в таблице 1 .

Таблица 1 - Характеристика тестовых участков и использованных изображений высокого пространственного разрешения

\begin{tabular}{|c|c|c|c|c|c|c|}
\hline \multirow[b]{2}{*}{$\begin{array}{l}\text { Тестовый } \\
\text { участок }\end{array}$} & \multirow[b]{2}{*}{$\begin{array}{c}\text { Число } \\
\text { пробных } \\
\text { площцадей }\end{array}$} & \multirow[b]{2}{*}{$\begin{array}{c}\text { Даты } \\
\text { пожсаров }\end{array}$} & \multirow[b]{2}{*}{$\begin{array}{c}\text { Даты наземного } \\
\text { наблюдения }\end{array}$} & \multicolumn{2}{|c|}{ Даты спутниковой съемки } & \multirow[b]{2}{*}{$\begin{array}{c}\text { Преобладающий тип } \\
\text { насаждений }\end{array}$} \\
\hline & & & & До пожсара & $\begin{array}{c}\text { Через несколько } \\
\text { лет после } \\
\text { пожара }\end{array}$ & \\
\hline $\begin{array}{l}\text { Красноярский } \\
\text { край }\end{array}$ & 17 & $\begin{array}{c}\text { июнь } \\
2012 \text { г. }\end{array}$ & 01.07 .2015 & 01.08 .2011 & 12.08.2015 & Кедр и пихта \\
\hline $\begin{array}{l}\text { Республика } \\
\text { Коми }\end{array}$ & 17 & $\begin{array}{c}\text { июль } \\
2013 \text { г. }\end{array}$ & 25.07.2015 & 29.06 .2013 & 06.08 .2015 & Сосна и ель \\
\hline
\end{tabular}

Наземные обследования проводились специалистами ФБУ «Российский центр защиты леса» и сопровождались закладкой пробных площадей, внутри которых для каждого дерева определялась его порода, диаметр и категория состояния. При этом выделялись следующие категории состояния деревьев: здоровые (1), ослабленные (2), сильно ослабленные (3), усыхающие (4), сухостой текущего года (5), сухостой прошлых лет (6). На пробной площади также производилась фотофиксация. На основе полученных данных для каждой пробной площади рассчитывалась средневзвешенная категория состояния (СКС), часто используемая при оценке состояния лесов: 


$$
\mathrm{CKC}=\frac{\sum_{\mathrm{i}=1}^{4} \mathrm{iK}_{\mathrm{i}}+5 \sum_{\mathrm{i}=5}^{6} \mathrm{~K}_{\mathrm{i}}}{\sum_{\mathrm{i}=1}^{6} \mathrm{~K}_{\mathrm{i}}}
$$

где $\mathrm{Ki}$ - число деревьев і-ой категории состояния деревьев согласно лесопатологической классификации.

Традиционно выделяют следующие верхние границы интервалов значений СКС для отнесения насаждения к категориям состояния: 1,5 - здоровое насаждение; 2,5 - ослабленное; 3,5 - сильно ослабленное; 4,5 - усыхающее. Насаждения со средневзвешенной категорией состояния выше 4,5 относятся к погибшим.

Полученная таким образом база наземных данных составила основу для исследований возможностей оценки состояния поврежденных пожарами лесов через несколько лет после воздействия огня на основе использования данных ДЗ3.

Исследования проводились на основе данных спутниковых систем Landsat- ETM+ и Landsat-OLI-TIRS. На исследуемые участки в системе Vega-Science [10,11] были подобраны безоблачные изображения, полученные до пожара и в 2015 г. в период вегетации (таблица 1). C помощью инструментов, доступных в системе были получены данные о спектральной отражательной способности земного покрова с последующим расчетом вегетационных индексов SWVI и RdSWVI:

$$
\begin{aligned}
& \text { SWVI }=\frac{\mathrm{R}_{\text {nir }} \mathrm{R}_{\text {swir }}}{\mathrm{R}_{\text {nir }}+\mathrm{R}_{\text {swir }}} \\
& \text { RdSWVI }=\frac{\mathrm{SWVI}_{\text {pre }} \text { SWVI }_{\text {post }}}{\text { SWVI }_{\text {pre }}^{+1}}
\end{aligned}
$$

где $\mathrm{R}_{\text {nir }}$ и $\mathrm{R}_{\mathrm{swir}}$ - значения коэффициента отражения земной поверхности в ближнем и среднем ИК диапазонах длин волн, $\mathrm{SWVI}$ pre и $_{\mathrm{SWVI}}$ post - значения индекса до и после воздействия пожара.

\section{Исследование отражательной способности лесов по спутниковым изображениям летнего периода съемки через несколько лет после пожара}

В ходе исследования были получены зависимости показателя СКС от вегетационного индекса RdSWVI, рассчитанного на основе спутниковых данных в соответствии с формулой (1). Полученные уравнения связи сравнивались с полученным нами ранее [3] уравнением, основанном на данных об отражательной способности лесов, измеренной непосредственно после воздействия огня: СКC=7.58*RdSWVI+1.47 (2).

Результаты показали, что на исследуемых пожарах обнаружена линейная зависимость параметра СКС от индекса RdSWVI. Коэффициент детерминации, этих линейных зависимостей для пробных площадей, заложенных в лесах Республики Коми и Красноярского края соответственно составили 0,86 и 0,87 . Обнаружено также, что уравнение зависимости СКС от индекса RdSWVI может значительно отличатся на разных участках, показывая различное отклонение от уравнения, полученного сразу после воздействия огня (2). Основанной причиной обнаруженных отличий является развитие напочвенного растительного покрова и соответствующее изменение спектрально-отражательных свойств лесного покрова. На рисунке 1 показаны графики зависимостей СКC от RdSWVI для поврежденных пожарами лесов в 
Республике Коми и в Красноярском крае, а также наземные фотографии погибших лесов $(\mathrm{CKC}=5)$, иллюстрирующие вероятную причину различий уравнения зависимости параметра СКC от индекса RdSWVI.
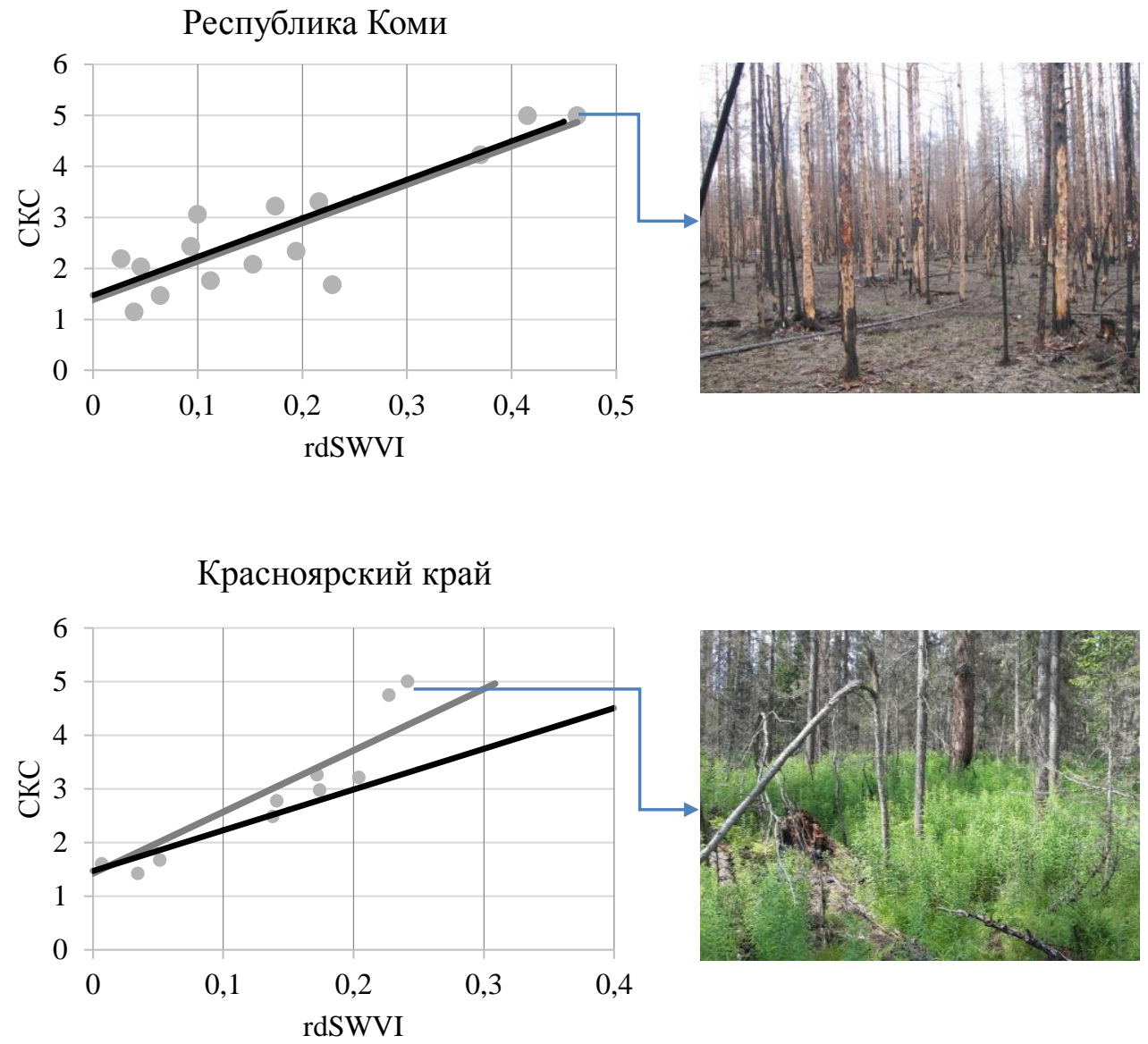

Рисунок 1. Графики зависимости СКС от RdSWVI для поврежденных пожарами лесов на тестовых участках в Республике Коми и Красноярском крае (серый цвет), зависимость СКС от RdSWVI по данным [3] (черная линия), а также фотографии пробных площадей $(\mathrm{CKC}=5)$

\section{Выводы}

Выполненные исследования показывают, что постпожарное развитие напочвенного растительного покрова может оказывать значительное влияние на коэффициенты уравнения связи характеристик состояния лесов и спектральных вегетационных индексов, что требует разработки соответствующих методов учета данного фактора при многолетней дистанционной оценке поврежденных пожарами лесов.

Исследование выполнено за счет гранта Российского научного фонда (проект № 19-77-30015). 


\section{References}

[1] Lupyan E.A., Bartalev S.A., Balashov I.V., Egorov V.A., Ershov D.V., Kobets D.A., Sen'ko K.S., Stytsenko F.V., Sychugov I.G. Satellite monitoring of forest fires in the 21 st century in the territory of the Russian Federation (facts and figures based on active fires detection), Sovremennye problemy distantsionnogo zondirovaniya Zemli iz kosmosa, 2017, 13(6), pp. 158-175. DOI: 10.21046/2070-7401-2017-14-6-158-175. (In Russian).

[2] Isaev A.S., Korovin G.N., Bartalev S.A., Ershov D.V., Janetos A.S., Kasischke E.S., Shugart H.H., French N.H., Orlick B.E., Murphy T.L. Using Remote Sensing to Assess Russian Forest Fire Carbon Emissions, Climate Change, 2002, 55 (1-2), pp.235-249.

[3] Bartalev S.A., Stytsenko F.V., Egorov V.A., Lupyan E.A. An assessment of Russian forest fire mortality using satellite data, Lesovedenie, 2015, 2, pp. 83-94. (In Russian).

[4] Allen, J.L.; Sorbel, B. Assessing the differenced Normalized Burn Ratio's ability to map burn severity in the boreal forest and tundra ecosystems of Alaska's national parks, Int. J. Wildland Fire 2008, 17, pp. 463-475.

[5] Cai, W.; Yang, J.; Liu, Z.; Hu, Y.; Weisberg, P.J. Post-fire tree recruitment of a boreal larch forest in Northeast China, For. Ecol. Manag. 2013, 307, pp. 20-29.

[6] Cocke, E.A., Fule, P.Z., \& Crouse, J.E. Comparison of burn severity assessments using the Differenced Normalized Burn Ratio and ground data, International Journal of Wildland Fire, 2005, 14, pp. 189-198.

[7] Epting, J.; Verbyla, D. Landscape-level interactions of prefire vegetation, burn severity, and postfire vegetation over a 16-year period in interior Alaska, Can. J. For. Res., 2005, 35, pp. 1367-1377.

[8] Hoy, E.E.; French, N.H.; Turetsky, M.R.; Trigg, S.N.; Kasischke, E.S. Evaluating the potential of Landsat TM/ETM+ imagery for assessing fire severity in Alaskan black spruce forests, Int. J. Wildland Fire, 2008, 17, pp. $500-514$.

[9] Stytsenko F.V., Bartalev S.A., Egorov V.A., Lupyan E.A. Post-fire forest tree mortality assessment method using MODIS satellite data, Sovremennye problemy distantsionnogo zondirovaniya Zemli iz kosmosa, 2013, 10(1), pp.254-266. (In Russian).

[10] Bartalev S.A., Ershov D.V., Lupyan E.A., Tolpin V.A.Possibilities of satellite service VEGA using for different tasks of land ecosystems monitoring, Sovremennye problemy distantsionnogo zondirovaniya Zemli iz kosmosa, 2012. 9(1), pp. 49-56. (In Russian).

[11] Loupian E.A., Proshin A.A., Burtsev M.A., Balashov I.V., Bartalev S.A., Efremov V.Yu., Kashnitskiy A.V., Mazurov A.A., Matveev A.M., Sudneva O.A., Sychugov I.G., Tolpin V.A., Uvarov I.A. IKI center for collective use of satellite data archiving, processing and analysis systems aimed at solving the problems of environmental study and monitoring, Sovremennye problemy distantsionnogo zondirovaniya Zemli iz kosmosa, 2015, 12(5), pp. 263-284. (In Russian). 